\title{
Links in the trophic chain: modeling functional relationships between in situ oceanography, krill, and blue whale distribution under different oceanographic regimes
}

\author{
Dawn R. Barlow ${ }^{1, *}$, Kim S. Bernard ${ }^{2}$, Pablo Escobar-Flores ${ }^{3}$, Daniel M. Palacios ${ }^{4}$, \\ Leigh G. Torres ${ }^{1}$ \\ ${ }^{1}$ Geospatial Ecology of Marine Megafauna Lab, Marine Mammal Institute, and Department of Fisheries and Wildlife, \\ Oregon State University, Newport, Oregon 97365, USA \\ ${ }^{2}$ College of Earth, Ocean, and Atmospheric Sciences, Oregon State University, Corvallis, Oregon 97331, USA \\ ${ }^{3}$ National Institute of Water and Atmospheric Sciences, Ltd., Wellington 6021, New Zealand \\ ${ }^{4}$ Marine Mammal Institute, and Department of Fisheries and Wildlife, Oregon State University, Newport, Oregon 97365, USA
}

\begin{abstract}
The response of marine predators to global climate change and shifting ocean conditions is tightly linked with their environment and prey. Environmental data are frequently used as proxies for prey availability in marine predator distribution models, as the ephemeral nature of prey makes sampling difficult. For this reason, the functional, ecological links between environment, prey, and predator are rarely described or explicitly tested. We used 3 years of vessel-based whale survey data paired with oceanographic sampling and hydroacoustic backscatter to model trophic relationships between water column structure, krill availability, and blue whale Balaenoptera musculus brevicauda distribution in New Zealand's South Taranaki Bight region under typical (2014 and 2017) and warm (2016) austral summer oceanographic regimes. The warm regime was characterized by a shallower mixed layer, and a stronger, thicker, and warmer thermocline. Boosted regression tree models showed that krill metrics predicted blue whale distribution (typical regime $=36 \%$ versus warm regime $=64 \%$ cross-validated deviance explained) better than oceanography (typical regime $=19 \%$ versus warm regime $=31 \%$ cross-validated deviance explained). However, oceanographic features that predicted more krill aggregations (typical regime) and higher krill density (warm regime) aligned closely with the features that predicted higher probability of blue whale presence in each regime. Therefore, this study confirms that environmental drivers of prey availability can serve as suitable proxies for blue whale distribution. Considering changing ocean conditions that may influence the distribution of marine predators, these findings emphasize the need for models based on functional relationships, and calibrated across a broad range of conditions, to inform effective conservation management.
\end{abstract}

KEY WORDS: Species distribution modeling - Blue whale $\cdot$ Balaenoptera musculus $\cdot$ Krill · Oceanography · Boosted regression trees · Marine predators - New Zealand - Marine heatwave · Climate change

\section{INTRODUCTION}

Global climate change is impacting marine organisms and ecosystems worldwide (Hoegh-Guldberg \& Bruno 2010, Hazen et al. 2013, Poloczanska et al. 2013,

${ }^{*}$ Corresponding author: dawn.barlow@oregonstate.edu
Sydeman et al. 2015). As mobile predators, the distribution patterns of marine mammals often reflect dynamic ecological processes by integrating multiple trophic levels (Croll et al. 1998, Nicol et al. 2000, Cotte et al. 2011). Therefore, the response of marine

(C) The authors 2020. Open Access under Creative Commons by Attribution Licence. Use, distribution and reproduction are unrestricted. Authors and original publication must be credited. 
mammals to changing ocean conditions is tightly linked to shifts in their environment and prey (Silber et al. 2017). The effective conservation of marine mammal populations challenged by climate change requires an ability to describe and predict their distribution patterns under changing oceanographic regimes. For such predictions to be informed and accurate, they should be founded on an understanding of the functional relationships between the physical and biological components of marine ecosystems, which can be accomplished in part through process-based models rooted in ecological understanding (Palacios et al. 2013, Silber et al. 2017).

Species distribution models (SDMs) are powerful analytical tools used to understand ecological relationships between species and their environment, and to predict spatial distributions of a species (Redfern et al. 2006, Elith \& Leathwick 2009, Derville et al. 2018). Prey are notoriously patchy and dynamic in the marine environment (Hyrenbach et al. 2000), and therefore difficult to sample. Hence, SDMs often rely on environmental features that can be relatively easily measured as predictor variables to describe the marine environment, such as remotely sensed temperature and primary productivity, with the assumption that these metrics serve as proxies for prey availability (Escobar-Flores et al. 2013, Becker et al. 2016, Hazen et al. 2017, Abrahms et al. 2019, Palacios et al. 2019). Although prey are acknowledged to be a primary driver of marine mammal distribution, the functional relationships between environmental features, prey availability, and predator distribution are rarely explicitly tested (Torres et al. 2008).

Blue whales Balaenoptera musculus are marine predators that forage in temperate ecosystems and selectively feed on krill (Croll et al. 2005, Hazen et al. 2015, Nickels et al. 2018). Foraging blue whales associate with areas characterized by cooler, productive waters as they often track upwelling areas and the distribution of their krill prey (Croll et al. 1998, 2005, Fiedler et al. 1998, Rennie et al. 2009, Pirotta et al. 2018, Abrahms et al. 2019, Palacios et al. 2019). In the California Current Ecosystem off the US west coast, the trophic pathway that leads to favorable foraging conditions for blue whales begins with longshore winds that drive upwelling of cold, nutrient-rich water, which drives primary productivity that sustains dense krill aggregations (Croll et al. 2005). The relatively short chain of events between oceanographic patterns, krill, and blue whales in such a system provides a suitable framework for investigating the functional trophic linkages between environment, prey, and predators in the marine environment.
A population of blue whales $B . m$. brevicauda was recently described that is genetically distinct, present in New Zealand waters year-round, and forages in the South Taranaki Bight region (STB, Fig. 1), which lies between the country's North and South Islands (Torres 2013, Barlow et al. 2018). The STB sustains New Zealand's most industrially active marine region, with ongoing oil and gas drilling and extraction, seismic exploration for petroleum reserves, and heavy shipping traffic (Torres 2013, Barlow et al. 2018). Information on the drivers of blue whale distribution and habitat use are needed to inform conservation management of the STB region and mitigate anthropogenic pressures on this newly described blue whale population and the ecosystem it inhabits.

The oceanography of the STB region is dominated by an upwelling system driven by winds off Kahurangi Point on the northwest coast of the South Island (Fig. 1), which generates a plume of cold water that moves to the northeast and into the STB (Shirtcliffe et al. 1990, Chiswell et al. 2017). The high primary productivity resulting from the cold water plume leads to the presence of large aggregations of the krill species Nyctiphanes australis (Bradford \& Chapman 1988, Bradford-Grieve et al. 1993), a known blue whale prey item in the Australasian region (Gill 2002). Blue whales use the STB region for multiple critical lifehistory functions including foraging (Barlow et al. 2018), which provides energetic sustenance for individual needs and population growth. The STB region harbors the largest and most consistent wind-driven upwelling system within New Zealand's coastal waters (Stevens et al. 2019), making it oceanographically unique, and providing an important foraging habitat for blue whales.

With multiple anthropogenic threats in the STB and increasing impacts of climate change across the New Zealand region, including recurring warm water anomalies (Sutton \& Bowen 2019), managers need reliable information on blue whale ecology and distribution patterns to balance species protection with industrial activities. The habitat and distribution of marine predators is predicted to shift with climate change, including range contraction and reduction in potential habitat for blue whales (Hazen et al. 2013, Schumann et al. 2013). A critical first step toward successful management is understanding the functional relationships between oceanography, prey, and predators. As spatial distribution patterns will likely shift under changing ocean conditions, it is important to examine ecological relationships under different climatic regimes and investigate how distribution models can be improved to more 

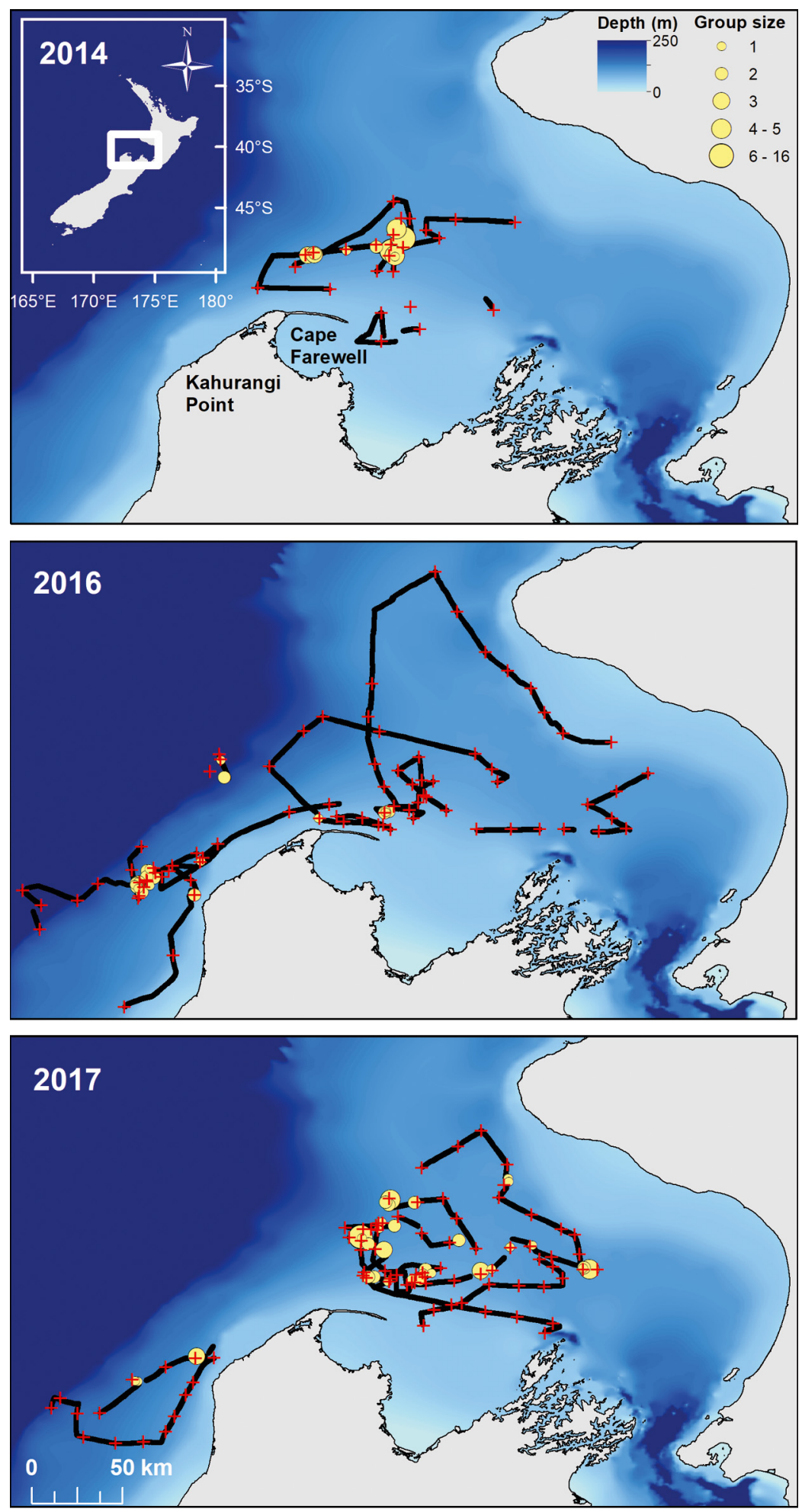

Fig. 1. Survey effort in the South Taranaki Bight (STB) region of New Zealand in each of the 3 study years. Black lines represent vessel tracklines during survey effort. Yellow circles represent blue whale sighting locations, scaled by number of blue whales recorded. CTD casts are shown as red crosses. Inset map of New Zealand in the 2014 panel indicates the location of the STB region within the white box accurately capture future climate change scenarios. Therefore, management strategies that are spatially and temporally dynamic, including regulatory boundaries that are not static but rather adaptable, will be better suited to protect marine ecosystems under changing oceanographic conditions (Hyrenbach et al. 2000, Maxwell et al. 2014).

Here we used 3 summer field seasons $(2014,2016$, and 2017) of blue whale, oceanography, and prey field data collected within the STB region to conduct an in-depth analysis of the functional links between water column structure, prey availability, and blue whale distribution. We hypothesized that (1) oceanographic features of the water column define krill availability, (2) blue whale distribution patterns reflect this variation in prey availability and habitat quality, and thus (3) oceanographic patterns can be used as reliable proxies of prey availability in models of blue whale distribution. The STB region experienced an extremely warm sea surface temperature anomaly and a regional marine heatwave during our data collection in 2016 (Oliver et al. 2017, Sutton \& Bowen 2019), which allows us to closely examine and compare functional relationships between environment, prey, and predator during dramatically different oceanographic regimes. Our findings demonstrate the need to establish functional relationships as the foundation of management decisions regarding the conservation of marine predators given rapidly changing ocean conditions, which can be validated and adapted as more data become available.

\section{MATERIALS AND METHODS}

\subsection{Survey methods}

Vessel-based visual surveys for blue whales were conducted in the austral summers of 2014, 2016, and 2017 in 
the STB region (Fig. 1). A $14 \mathrm{~m}$ jet-propelled catamaran equipped with a flying bridge $(4.0 \mathrm{~m}$ above the water line) for observational work was used as the research platform for the 2014 and 2016 field seasons. In 2017, the research platform was a $19.2 \mathrm{~m}$ vessel outfitted with a comparable height flying bridge (3.8 $\mathrm{m}$ above the water line). The research goals required maximization of encounter rates with blue whales. Therefore, prior to each survey day, daily images of remotely sensed sea surface temperature and chlorophyll a concentration were assessed to locate areas of upwelled water and high surface productivity. Surveys did not use a randomized design but were rather directed toward productive or previously unsurveyed areas. Visual search effort for blue whales was conducted at vessel speeds of 8 to 12 knots in acceptable weather conditions (Beaufort Sea State $<5)$. During the surveys, a minimum of 2 observers were stationed on the flying bridge, with the port observer covering $5^{\circ}$ to $-90^{\circ}$ from the bow, and the starboard observer covering $-5^{\circ}$ to $90^{\circ}$. Additional observers surveyed the entire area $\left(-90^{\circ}\right.$ to $\left.90^{\circ}\right)$. Whenever a whale was sighted, visual search effort was paused, and the date, time, location, and number of blue whales were recorded. At each sighting, whales were approached for photo-identification, biopsy sample collection, and behavioral observation via unmanned aerial systems (Barlow et al. 2018, Torres et al. 2020). After data collection at each sighting, search effort was directed to previously unsurveyed areas to minimize repeated encounters of the same individual whales and to maximize spatial coverage.

Survey effort was not continuous throughout each field season due to intermittent strong wind and weather events that resulted in interruptions. These weather events also potentially influenced oceanography in the study region. Therefore, an identifier of 'period' was applied for each segment of consecutive survey days. Over the 3 summer survey seasons, there were a total of 12 periods of sampling effort, ranging in length from 1-4 days (Table 1).

\subsection{Oceanographic data}

Temperature, salinity, and fluorescence data were recorded using a conductivity, temperature, and depth (CTD) sensor (Sea-Bird SBE 911plus) that was lowered from the vessel at a rate of $1 \mathrm{~m} \mathrm{~s}^{-1}$ until approximately $10 \mathrm{~m}$ off the bottom. At the start of each cast, the CTD was soaked for 1 min to adjust to the water conditions. CTD casts were performed at the start and end of visual search effort on each day, approximately every hour during visual search effort, and at all blue whale sightings (Fig. 1). The CTD was equipped with a fluorometer during the 2014 and 2017 seasons, but no fluorescence data were collected during 2016.

Readings from CTD profiles were binned into $0.5 \mathrm{~m}$ increments. Fourteen different oceanographic metrics were calculated from each CTD cast, describing the vertical structure of the water column (Table 2). Surface measurements were taken at $2 \mathrm{~m}$ below the surface for all metrics except salinity in 2016, which was taken at $4 \mathrm{~m}$ depth as shallower readings were erroneous. The mixed layer was defined as the depth at which temperature was $0.5^{\circ}$ lower than the surface temperature. The thermocline was defined as portion of the water column extending from the base of the mixed layer to the depth at which the temperature

Table 1. Summary of data collection effort in the South Taranaki Bight region of New Zealand during each survey period in 2014, 2016, and 2017

\begin{tabular}{|c|c|c|c|c|c|c|c|}
\hline Year & Period & $\begin{array}{l}\text { Start date } \\
\text { (d-mo-yr) }\end{array}$ & $\begin{array}{l}\text { End date } \\
\text { (d-mo-yr) }\end{array}$ & $\begin{array}{c}\text { Blue whale } \\
\text { sightings }\end{array}$ & $\begin{array}{l}\text { Background } \\
\text { points }\end{array}$ & $\begin{array}{l}\text { CTD } \\
\text { casts }\end{array}$ & $\begin{array}{c}\text { Echosounder } \\
\text { hours }\end{array}$ \\
\hline \multirow[t]{3}{*}{2014} & 1 & $24-01-2014$ & $25-01-2014$ & 1 & 82 & 4 & 4.61 \\
\hline & 2 & 28-01-2014 & $29-01-2014$ & 7 & 39 & 10 & 8.55 \\
\hline & 3 & $02-02-2014$ & $03-02-2014$ & 2 & 46 & 11 & 9.53 \\
\hline \multirow[t]{5}{*}{2016} & 4 & 23-01-2016 & $26-01-2016$ & 6 & 98 & 34 & 19.13 \\
\hline & 5 & 29-01-2016 & 29-01-2016 & 0 & 15 & 10 & 7.05 \\
\hline & 6 & 01-02-2016 & $03-02-2016$ & 7 & 72 & 27 & 12.33 \\
\hline & 7 & $05-02-2016$ & $05-02-2016$ & 9 & 9 & 5 & 3.31 \\
\hline & 8 & $08-02-2016$ & $08-02-2016$ & 0 & 16 & 6 & 7.03 \\
\hline \multirow[t]{4}{*}{2017} & 9 & $05-02-2017$ & $05-02-2017$ & 0 & 15 & 9 & 6.51 \\
\hline & 10 & $08-02-2017$ & $11-02-2017$ & 15 & 100 & 32 & 28.53 \\
\hline & 11 & $16-02-2017$ & $16-02-2017$ & 4 & 19 & 11 & 5.91 \\
\hline & 12 & $18-02-2017$ & $20-02-2017$ & 13 & 73 & 29 & 37.41 \\
\hline Total & & & & 64 & 584 & 188 & 149.95 \\
\hline
\end{tabular}


Table 2. Oceanographic metrics derived from CTD casts, with definitions and units of measurement for each calculation. Definitions of the mixed layer and the thermocline were adapted from Fiedler (2010), and pycnocline depth was calculated using the definition of Fiedler et al. (2013). RFU: relative fluorescence unit

\begin{tabular}{|c|c|c|}
\hline Metric derived from CTD cast & Abbreviation & Definition (units) \\
\hline Difference in salinity & diffs & Maximum salinity reading - minimum salinity reading (ppt) \\
\hline Depth of maximum fluorescence & dmaxf & Depth of maximum measured fluorescence (m) \\
\hline Integral of fluorescence & intf & Sum of fluorescence readings along cast down to $60 \mathrm{~m}$ depth \\
\hline Integral of temperature & intt & Sum of temperature readings along cast down to $60 \mathrm{~m}$ depth \\
\hline Minimum salinity & minsal & Minimum recorded salinity value (ppt) \\
\hline Mixed layer depth & mld & Depth where temperature is $0.5^{\circ} \mathrm{C}$ lower than at surface $(\mathrm{m})$ \\
\hline Mixed layer depth temperature & mldt & Temperature at mixed layer depth $\left({ }^{\circ} \mathrm{C}\right)$ \\
\hline Pycnocline depth & $\mathrm{pd}$ & Depth of maximum difference in density over a $10 \mathrm{~m}$ vertical window \\
\hline Surface fluorescence & surff & Fluorescence at $2 \mathrm{~m}$ depth (RFU) \\
\hline Surface temperature & surft & Temperature at $2 \mathrm{~m}$ depth $\left({ }^{\circ} \mathrm{C}\right)$ \\
\hline Thermocline depth & $\mathrm{tz}$ & Depth at midpoint of thermocline layer $(\mathrm{m})$ \\
\hline Thermocline strength & ths & Mixed layer depth temp - thermocline bottom temp $\left({ }^{\circ} \mathrm{C}\right)$ \\
\hline Thermocline thickness & tht & Thermocline bottom depth - mixed layer depth (m) \\
\hline Thermocline temperature & $\mathrm{tt}$ & Temperature at midpoint of thermocline layer $\left({ }^{\circ} \mathrm{C}\right)$ \\
\hline
\end{tabular}

decreased halfway toward the deep-water temperature at the bottom of the cast (Fiedler 2010). The pycnocline was defined based on density (calculated from temperature and salinity), where the pycnocline depth was calculated as the depth with the maximum difference in density over a $10 \mathrm{~m}$ vertical window in the water column (Fiedler et al. 2013). Integrals of temperature and fluorescence were computed for depths up to $60 \mathrm{~m}$ to standardize among casts, and casts shallower than $60 \mathrm{~m}(\mathrm{n}=6)$ were not given a value for integral of temperature or fluorescence.

For each survey period, oceanographic metrics were spatially interpolated using an inverse distance weighting technique, which preserves local variation between sample points. Each metric was interpolated using all CTD casts within each period and a $25 \mathrm{~km}$ search radius, to the extent of a $50 \mathrm{~km}$ buffer around the ship's survey tracks for that period. Each interpolation produced a raster grid of $4 \mathrm{~km}$ resolution. All interpolations of oceanographic metrics were conducted in ArcMap v. 10.7.1.

\subsection{Prey data}

During visual search effort and at 53 blue whale sighting locations, hydroacoustic backscatter data were collected using a single frequency $(120 \mathrm{kHz})$ Simrad split-beam ES-60 echosounder. The transceiver settings used for data collection were $250 \mathrm{~W}$ power, $1.024 \mathrm{~ms}$ pulse length, and $0.5 \mathrm{~s}$ ping rate. The transducer was lowered $1.26 \mathrm{~m}$ below the surface in 2014 and 2016, and $1.45 \mathrm{~m}$ below the surface in 2017. It was not always possible to run the trans- ducer during the surveys due to logistical constraints such as rough weather and swell conditions; therefore, the spatial coverage of prey data was more limited than that of oceanography or whale distribution data.

Raw acoustic backscatter data were processed using the opensource software ESP3 (https://sourceforge.net/ projects/esp3/), developed for fisheries hydroacoustic analysis. Volume backscattering strength $\left(S_{\mathrm{v}}\right)$ was echo-integrated in $1 \mathrm{~m}$ depth by 5-ping horizontal bins. The upper $2 \mathrm{~m}$ of the water column were excluded from the analysis to exclude the transducer near-field and surface noise. Likewise, sections with recognizable interference from CTD casts or missed pings were excluded. Following complete visual inspection of the echograms for quality control, measurements made at $2 \mathrm{~m}$ or deeper were retained for analysis.

Backscatter from zooplankton-like schools was identified by excluding ping data with $S_{\mathrm{v}}$ below $-90 \mathrm{~dB}$ at $120 \mathrm{kHz}$. The threshold value applied is more conservative than those used in similar analyses for larger krill species with established cutoff frequencies (e.g. Euphausia superba, Bernard \& Steinberg 2013). This threshold reliably identified and captured aggregations visible on the echosounder, thereby effectively characterizing schools within this ecosystem. Recognizing the inability to definitively exclude other ensonified species (i.e. fish) with a single frequency, and in the absence of a known target strength for the krill species of interest (Nyctiphanes australis), it was assumed that the acoustically identified aggregations using the selected threshold value were predominately comprised of krill. Krill aggregations were defined 
following the methods described by Bernard et al. (2017). Each element in the acoustic matrix that qualified as krill was considered to be part of an 'aggregation' if 1 of its 8 neighboring elements also qualified as krill (Lawson et al. 2008, Bernard \& Steinberg 2013, Bernard et al. 2017).

For each krill aggregation, date, time, and geographic location were extracted and mean $S_{\mathrm{v}}$, depth, and width (vertical thickness) were calculated. The aggregations were subsequently plotted in ArcMap by period, and overlaid with a $4 \mathrm{~km}$ grid consistent with the oceanographic interpolation raster grids. The number of krill aggregations (count), mean $S_{\mathrm{v}}$, median depth, maximum depth, and mean width were calculated for all aggregations within each 4 $\mathrm{km}$ grid cell to generate a raster layer for each krill metric in each period. The raster describing the number of krill aggregations was standardized by the amount of echosounder survey time spent in each grid cell to compensate for uneven survey effort across the region, such as while at blue whale sighting locations when the echosounder continued to collect data. This standardization was accomplished by dividing the number of krill aggregations by log (number of pings) for each $4 \mathrm{~km}$ grid cell. The logtransformation was applied because the number of pings per cell was highly skewed by the length of time spent in certain cells during blue whale sightings. To test for the presence of spatial autocorrelation among the krill metrics when summarized over a $4 \mathrm{~km}$ spatial scale, Moran's I-tests were run for each krill metric in each year using the 'ape' package in $\mathrm{R}$ (Paradis \& Schliep 2019).

\subsection{Species distribution modeling}

Based on the observed marine heatwave with broadscale sea surface temperature anomalies in 2016 (Oliver et al. 2017, Sutton \& Bowen 2019), the frequency distributions of all krill and oceanographic metrics were examined prior to modeling to assess variation between the 3 survey years. This a priori knowledge was used to inform model generation, fit robust and relevant models, and compare outputs.

SDMs are multivariate algorithms that combine species occurrence data with environmental conditions to gain ecological insight and predict spatial distributions of a species (Redfern et al. 2006, Elith \& Leathwick 2009). Boosted regression trees (BRTs) are a machine learning SDM framework that combines decision tree methods (models that partition predictor space by recursive binary splits) with a boosting algorithm that iteratively optimizes model performance by combining a large number of decision trees (Elith et al. 2008). The boosting algorithm minimizes model overfitting by introducing stochasticity through withholding a random selection of the data at each step during model fitting (Elith et al. 2008). The BRT approach is well-suited for modeling non-linear ecological relationships and detecting complex interactions between predictor variables (Elith et al. 2008), and was therefore implemented in this study rather than linear or additive regression modeling approaches.

Three suites of models were tested in this study (Table 3). First, relationships between krill metrics and whale distribution were assessed to determine the most influential metrics (whales $\sim$ krill models). Subsequently, relationships between oceanographic metrics and the significant krill metrics from the whales $\sim$ krill models were assessed to identify and describe influential patterns (krill oceanography models). Lastly, to examine how oceanographic features influence whale distribution, and determine if the patterns reflect oceanographic drivers of krill, the relationships between blue whales and oceanography were explored in a third set of models (whales oceanography models). It should be clarified that these models are not mechanistic models of trophic interactions, but rather models of distinct steps in the food chain for comparison of influential predictor variables and functional response curves.

For the whales $\sim$ krill and whales $\sim$ oceanography models, blue whale habitat use was modeled with presence/background data as the binomial response variable. Presence locations were the points where blue whales were sighted. Absence data were collected continuously during visual search effort and are therefore represented by the areas surveyed by the vessel. Background points for locations without whales (also called 'pseudo-absences') were generated by creating a buffer around the research vessel's track and generating point locations within that buffer (Torres et al. 2008, Derville et al. 2018). Buffer width was determined by Beaufort Sea State (BSS; Kinsman 1969) to account for the visual detection range of the observers in variable survey conditions (Barlow et al. 2001) (BSS0 $=10 \mathrm{~km}$, $\mathrm{BSS} 1=8 \mathrm{~km}, \mathrm{BSS} 2=6 \mathrm{~km}, \mathrm{BSS} 3=4 \mathrm{~km}, \mathrm{BSS} 4=2$ $\mathrm{km}$, BSS5 = $1 \mathrm{~km}$; buffer width applied to both sides of the vessel track). Background points were pseudo-randomly generated within the vessel track buffer for each period at a minimum distance of 5 $\mathrm{km}$ apart to avoid serial correlation between background points, and their distribution within the 
Table 3. Final boosted regression tree results for the 3 trophically linked models in each regime, relative contribution of each predictor variable, and model performance evaluated using cross-validated percent deviance explained (CV deviance explained) and area under the receiver operating curve (AUC). Note that for the krill oceanography models, the response variable in the typical regime model is the number of krill aggregations, whereas in the warm regime model, the response variable is aggregation density $\left(S_{\mathrm{v}}\right)$

\begin{tabular}{|c|c|c|c|c|}
\hline Model & Regime & Predictors (\% contribution) & CV \% deviance explained & AUC \\
\hline \multirow[t]{2}{*}{ Whales krill } & Typical & $\begin{array}{l}\text { Number of aggregations (50.4) } \\
\text { Aggregation density }(24.8) \\
\text { Maximum aggregation depth (14.2) } \\
\text { Aggregation width (10.6) }\end{array}$ & 31.3 & 0.71 \\
\hline & Warm & $\begin{array}{l}\text { Aggregation density (48.7) } \\
\text { Aggregation width (29.6) } \\
\text { Median aggregation depth (22.5) }\end{array}$ & 60.2 & 0.87 \\
\hline \multirow[t]{2}{*}{ Krill oceanography } & $\begin{array}{l}\text { Typical } \\
\text { (standardized number } \\
\text { of aggregations) }\end{array}$ & $\begin{array}{l}\text { Mixed layer depth }(29.9) \\
\text { Thermocline strength }(20.9) \\
\text { Thermocline thickness }(13.0) \\
\text { Difference in salinity }(12.9) \\
\text { Thermocline temperature }(12.1) \\
\text { Integral of temperature }(7.0) \\
\text { Pycnocline depth }(4.0)\end{array}$ & 16.7 & N/A \\
\hline & $\begin{array}{l}\text { Warm } \\
\text { (aggregation density } \\
\left(\mathrm{S}_{\mathrm{v}}\right) \text { ) }\end{array}$ & $\begin{array}{l}\text { Thermocline strength }(25.2) \\
\text { Thermocline temperature }(16.4) \\
\text { Thermocline thickness }(13.9) \\
\text { Pycnocline depth (12.9) } \\
\text { Difference in salinity (11.0) } \\
\text { Integral of temperature (10.4) } \\
\text { Mixed layer depth (10.1) }\end{array}$ & 14.4 & N/A \\
\hline \multirow[t]{2}{*}{ Whales $~$ oceanography } & Typical & $\begin{array}{l}\text { Thermocline strength }(27.7) \\
\text { Thermocline thickness }(22.8) \\
\text { Thermocline temperature (14.6) } \\
\text { Mixed layer depth (11.7) } \\
\text { Pycnocline depth }(9.7) \\
\text { Integral of temperature }(7.4) \\
\text { Difference in salinity }(6.2)\end{array}$ & 26.6 & 0.69 \\
\hline & Warm & $\begin{array}{l}\text { Difference in salinity (47.0) } \\
\text { Water depth (23.2) } \\
\text { Thermocline thickness (7.4) } \\
\text { Mixed layer depth (5.7) } \\
\text { Integral of temperature (5.2) } \\
\text { Pycnocline depth (4.8) } \\
\text { Thermocline strength (3.5) } \\
\text { Thermocline temperature (3.1) }\end{array}$ & 36.5 & 0.87 \\
\hline
\end{tabular}

buffer was irrespective of the location of presence points (Derville et al. 2018). The number of background points generated was proportional to the amount of time spent on survey effort within each period (no. background points $=$ no. minutes survey effort in period); to evenly reduce the number of background points to a useful size, this number was divided by 20 (Derville et al. 2018). Ultimately, the resulting binomial dataset for all 3 survey years was comprised of 64 presence points and 584 background points (Table 1). During BRT model fitting, presence points were weighted by the number of blue whales at each sighting. Background points were down-weighted so that the sum of all background points was equal to the sum of all groups of whales encountered during survey effort, as equally weighting presence and background data has been demonstrated to increase accuracy of species distribution models (Barbet-Massin et al. 2012)

For the krill oceanography models, the response variable was continuous (Gaussian). The krill metrics with the greatest contribution to the whales $\sim$ krill models were modeled as a function of the oceanographic predictor variables, and to do so, all oceanographic variables were sampled within all grid cells with krill data, for each survey period. Using the 
raster grid layers of each krill metric, the oceanographic metrics were sampled at the centroid of each grid cell for each period.

BRT models were fit using the 'gbm' v.2.1.5 (Greenwell et al. 2019) and 'dismo' v.1.1-4 (Hijmans et al. 2017) packages and visualized using the 'pdp' (Greenwell 2017) package implemented in the $\mathrm{R}$ statistical software v.3.6.1 (R Core Team 2019). The bag fraction (proportion of data that are drawn at random at each step) was set to 0.75 . The tree complexity ( $\mathrm{TC}$; number of interactions allowed) was tested using values ranging between 1 and 3 . Low values for TC were chosen as ecological interpretation of multiple interactions becomes increasingly difficult. Final TC was 1 for the whales $\sim$ krill models and 2 for the krill oceanography and whales $~$ oceanography models, and these values were selected based on model performance metrics. Learning rate (contribution of each tree to the model) was started at 0.01 and allowed to increase until the optimal number of trees was reached (>1000; Elith et al. 2008). BRT outputs include an estimate of the relative influence of each predictor variable, based on the number of times the variable is selected for splitting, and weighted by the improvement to the model as a result of each split (Friedman \& Meulman 2003). As it has been demonstrated that the inclusion of predictor variables with $<3 \%$ contribution has negligible impact on overall model performance (Elith et al. 2008), variables with relative contribution below this threshold were removed from the model.

All models were evaluated using the cross-validated percent deviance explained by the model (CV deviance explained). Using a cross-validation procedure run during the BRT modeling process, CV deviance explained indicates how well a model predicts the subsets of withheld data (Buston \& Elith 2011). Therefore, CV deviance explained is a useful metric for evaluating SDMs, as it balances model fit and complexity through cross-validation during the modeling process (Torres et al. 2013). For the binomial models (whales $\sim$ krill and whales $\sim$ oceanography), model performance was also evaluated using the area under the receiver operating characteristic curve (AUC). The receiver operating characteristic curve measures the true negative rate against the true positive rate at various discrimination thresholds. AUC represents the ability of models to classify between presence and background points, by measuring discrimination across all possible thresholds between 0 and 1, with AUC > 0.7 considered a 'useful' model (Swets 1988).
While BRTs can theoretically handle correlated predictor variables (Elith et al. 2008), manually removing redundant variables is desirable, particularly when working with small datasets (Elith et al. 2008, Derville et al. 2016). A correlation analysis was conducted to examine pairwise relationships between all krill metrics and, separately, all oceanographic metrics to remove highly correlated predictor variables in the models. For pairs of variables with a Pearson's correlation coefficient $\geq 0.7$, only 1 of the 2 was included in the model at a time. All models were run with all possible combinations of non-correlated predictor variables, and validation metrics (CV deviance explained and AUC) were evaluated to select the combination of predictors that produced the best model performance.

Since fluorescence profiles were measured in 2014 and 2017, but not 2016, all models were initially run without any fluorescence metrics to allow for comparison across years. Subsequently, fluorescence metrics were included in the krill oceanography and whales oceanography models using only 2014 and 2017 data to investigate whether the inclusion of fluorescence data improved model performance based on evaluation metrics.

\section{RESULTS}

\subsection{Inter-annual differences}

Oceanographic metrics derived from CTD data were dramatically different in 2016 compared to 2014 and 2017 (Fig. S1 in the Supplement at www.int-res.com/ articles/suppl/m642p207_supp.pdf), reflecting 2 very different oceanographic regimes. During 2016, the oceanography was characterized by a much shallower mixed layer depth, higher integral of temperature, stronger thermocline, and higher thermocline temperature than in 2014 or 2017 (Fig. 2). The Moran's I-tests revealed no significant spatial autocorrelation among the krill metrics summarized per $4 \mathrm{~km}$ grid cell in any year, with the exception of aggregation density in 2016 (Table S1). Like the oceanographic metrics, the krill metrics were also different between 2016 and 2014/17 (Fig. S2), with 2016 having fewer krill aggregations that were less dense and were found deeper in the water column than in 2014 or 2017 (Fig. 3). Additionally, while the differences amongst the krill metrics were not as striking between years as the oceanographic metrics, the spatial distribution of krill was different between the 2 oceanographic regimes of 2016 and 2014/17 (Fig. 4). The region of 

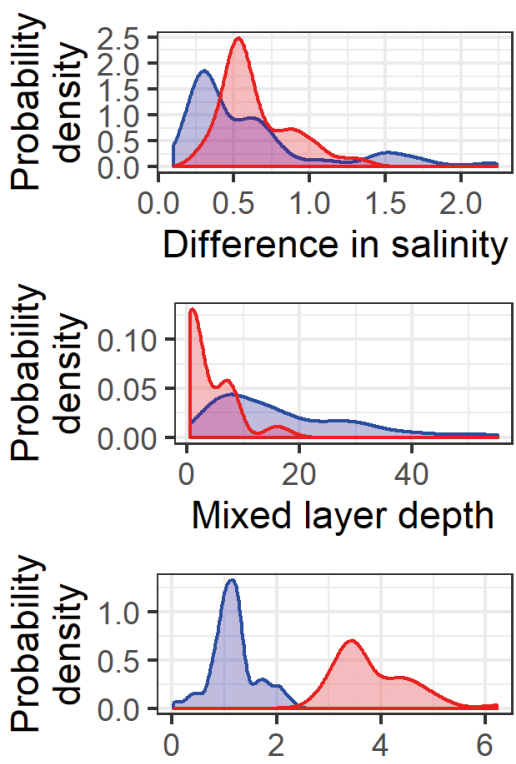

Thermocline strength

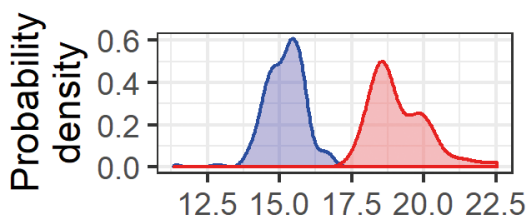

Thermocline temperature

Fig. 2. Probability density plots comparing the distribution of oceanographic metrics calculated from CTD profiles in the South Taranaki Bight region (STB) in the typical (2014 and 2017, blue) and warm (2016, red) oceanographic regimes
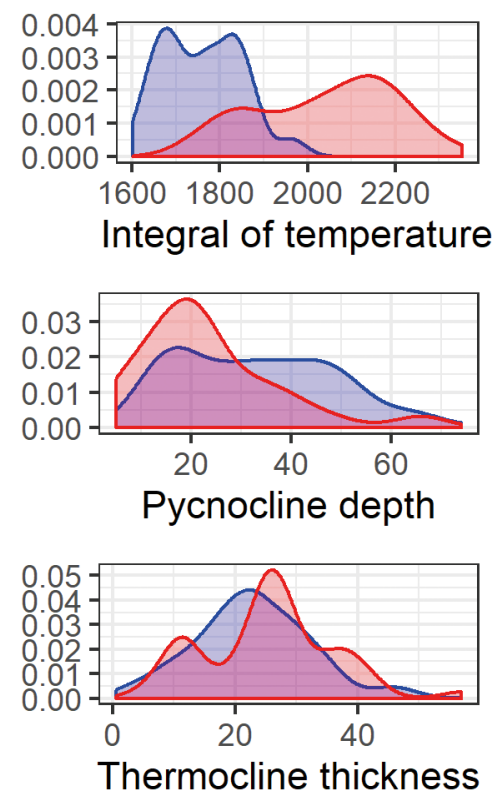

Thermocline thickness the STB north of Cape Farewell had more dense krill aggregations and high numbers of krill aggregations in both 2014 and 2017, which were rare or absent during the 2016 survey. The spatial distribution of blue whale sightings also differed between years. In 2014 and 2017, many sightings took place north of Cape Farewell, whereas very few sightings were made in that area in 2016 and the whales were distributed more offshore in the western STB region (Fig. 1). Therefore, 2 sets of BRTs were generated based on oceanographic regime to isolate and compare drivers of distribution patterns under different conditions: typical (2014 and 2017 data grouped together) and warm (2016).

\subsection{Species distribution modeling}

The correlation analysis revealed no or very weak correlations among krill metrics (Pearson's correlation coefficient $=0.02-0.43$ ), and several strong correlations among oceanographic metrics (Fig. S3). A total of 12
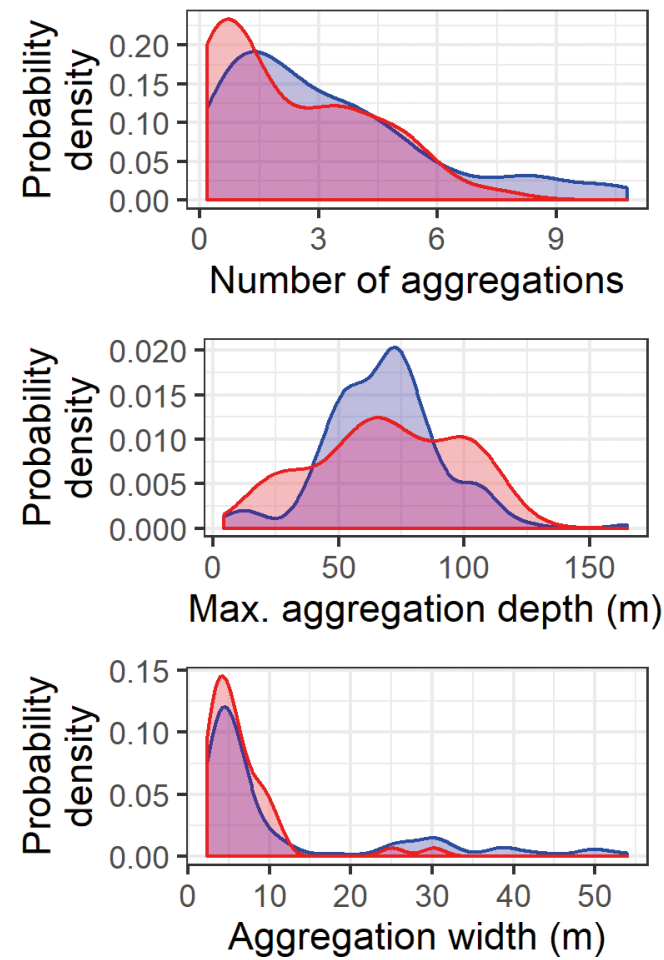
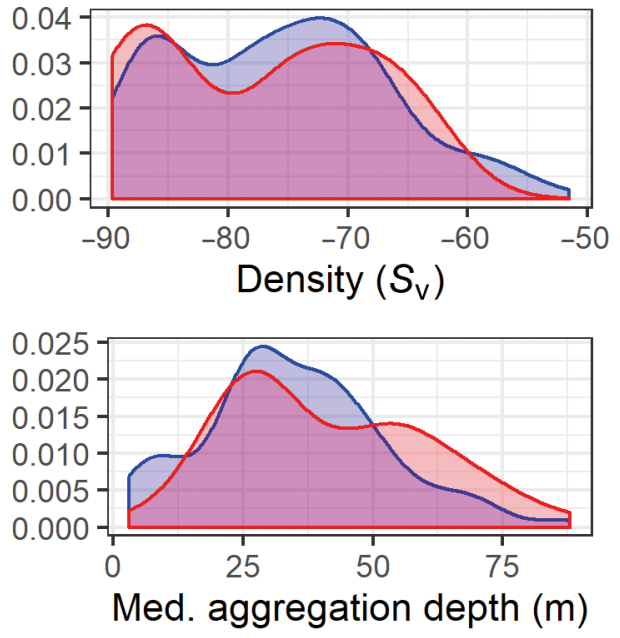

Fig. 3. Probability density plots comparing the distribution of krill metrics derived from echosounder data collected in the South Taranaki Bight region (STB) in the typical (2014 and 2017, blue) and warm (2016, red) oceanographic regimes 

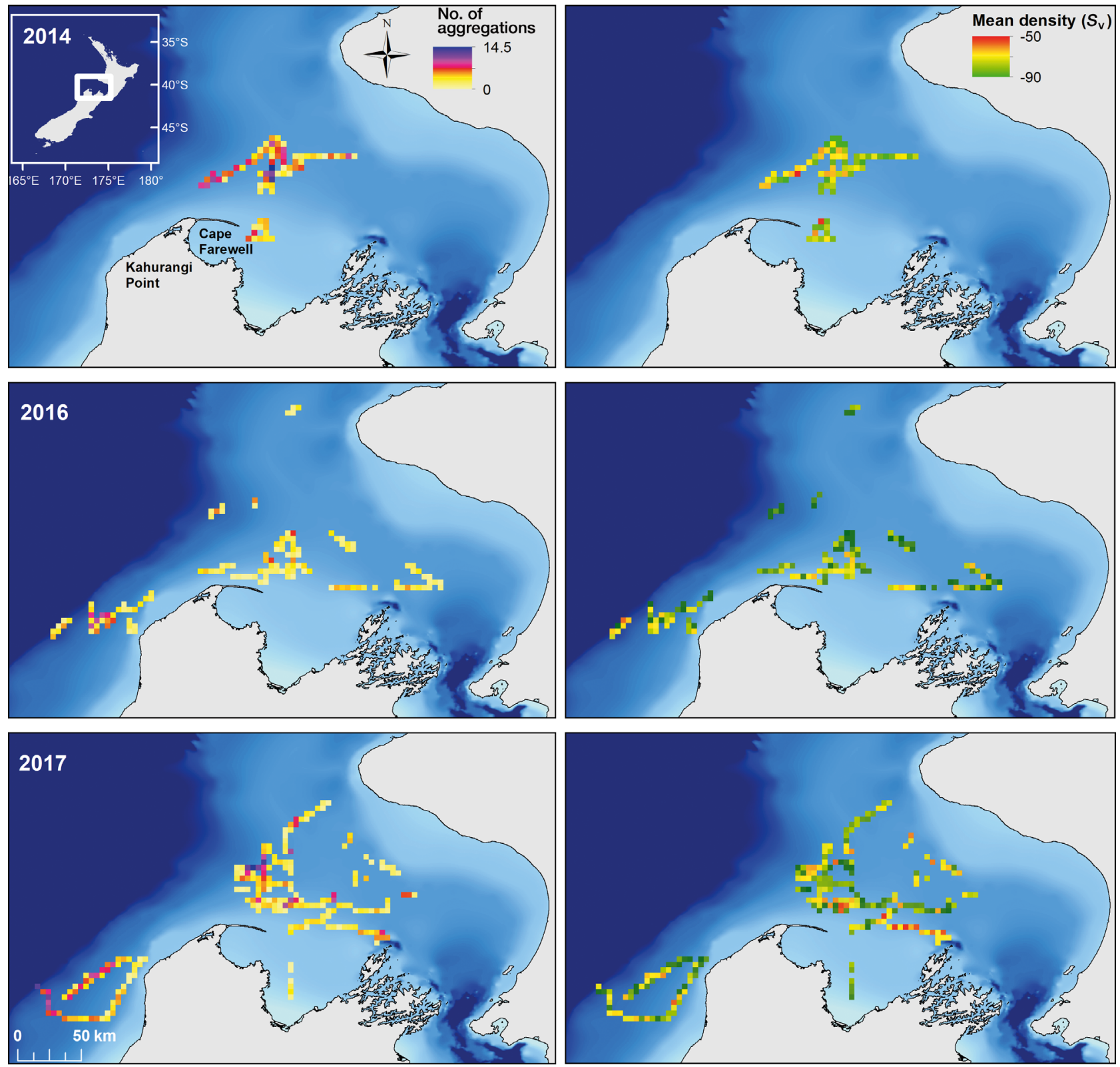

Fig. 4. Spatial distribution of the standardized number of krill aggregations (left column) and krill aggregation density (right column) in each of the 3 survey years in the South Taranaki Bight region (STB). For number of aggregations, the total number of aggregations was counted within each $4 \mathrm{~km}$ grid cell and standardized by the amount of echosounder survey time spent in each grid cell to compensate for uneven sampling effort. For krill density $\left(S_{\mathrm{v}}\right)$, the mean was calculated for all aggregations in each grid cell. A minimum-maximum stretch type with a gamma stretch of 1.5 was applied for visualization

possible combinations of oceanographic predictors were tested for all 3 suites of models, for both the typical and warm regimes. Overall, the combination of predictor variables that yielded the best model performance and most consistent results across all models was diffs, intt, mld, pd, ths, tht, $\mathrm{tt}$, and water depth (see Table 2 for definitions); however, not all of these metrics were included in the final models, as predictors were removed if their contribution was $<3 \%$ (Table 3 ).

For the whales $\sim$ krill model in the typical regime, $31.3 \%$ of the CV deviance could be explained by 4 krill metrics: number of aggregations, aggregation density $\left(S_{\mathrm{v}}\right)$, maximum aggregation depth, and aggregation width (Fig. 5). In the warm regime, $60.2 \%$ of the CV deviance was explained by $S_{\mathrm{v}}$ 


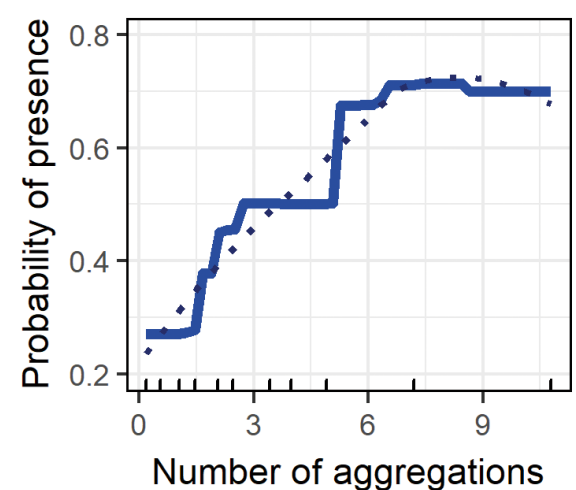

$(50.4 \%)$
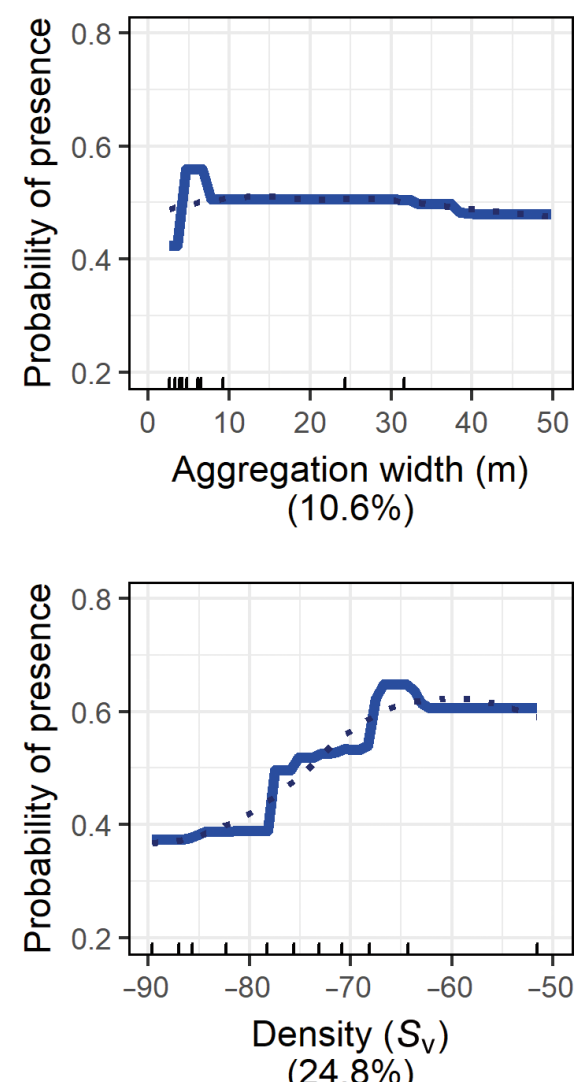

(24.8\%)

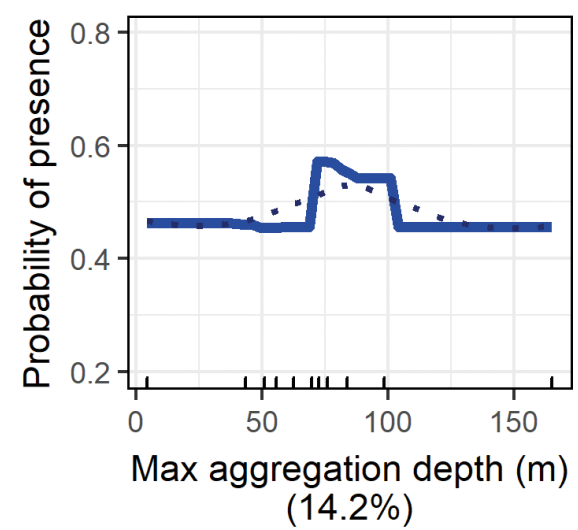

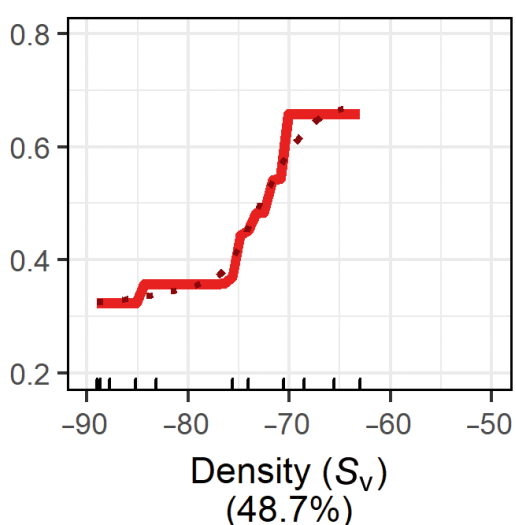
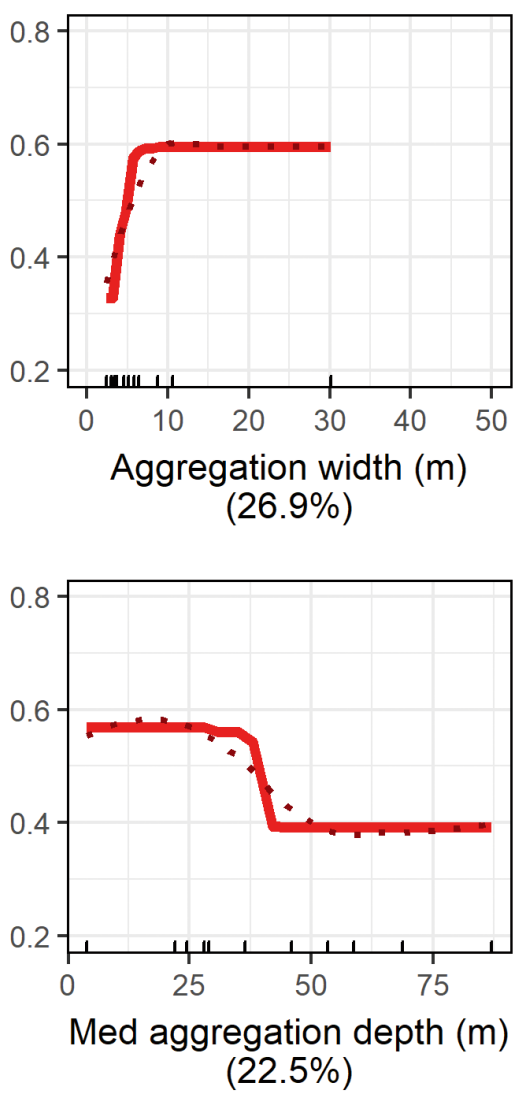

Fig. 5. Boosted regression tree partial dependency plots for predictor variables of blue whale presence from the whales $\sim$ krill models under typical (blue) and warm (red) oceanographic regimes. Each plot shows the effect of a predictor variable on the probability of presence while fixing other variables to their mean value; parentheses: contribution to the model; dotted lines: smoothed fitted function for each relationship; rug plots: distribution of values for each predictor in deciles aggregation width, and median aggregation depth (Fig. 5). AUC scores were 0.71 in the typical regime, and 0.87 in the warm regime. While number of aggregations had by far the greatest contribution to the model in the typical regime $(50.4 \%$; Fig. 5, Fig. S4), number of aggregations was not retained in the whales $\sim$ krill model under the warm regime. Instead, $S_{\mathrm{v}}$ had the greatest contribution to the model in the warm regime (48.7\%; Fig. 5).

For the krill oceanography models, different krill metrics were modeled as the response variable in the 2 different regimes because results of the whales $\sim$ krill models indicated that 2 different krill metrics were the primary drivers of blue whale distribution under the different regimes. In the typical regime, number of aggregations was modeled relative to oceanography and had a CV deviance explained of $16.7 \%$. The number of aggregations was highest where mixed layer depth was either very shallow $(<5 \mathrm{~m})$ or deeper than $30 \mathrm{~m}$, where the thermocline was stronger and thicker, where the difference in salinity was greater (i.e. greater range in salinity values, indicating a stronger pycnocline), where the pycnocline was deeper, and where thermocline temperature was lower (Fig. 6). $S_{\mathrm{v}}$ was modeled to describe the oceanographic drivers of blue whale prey distribution during the warm regime, and produced a CV deviance explained of $14.4 \%$. In comparison to the functional relationships of number of aggregations during the typical regime, krill density in the warm year was also highest where the thermocline was stronger, difference in salinity was moderate, and thermocline temperature was lower, but in contrast decreased with increasing thermocline thickness and pycnocline depth (Fig. 6). However, it is important to highlight the dif- 

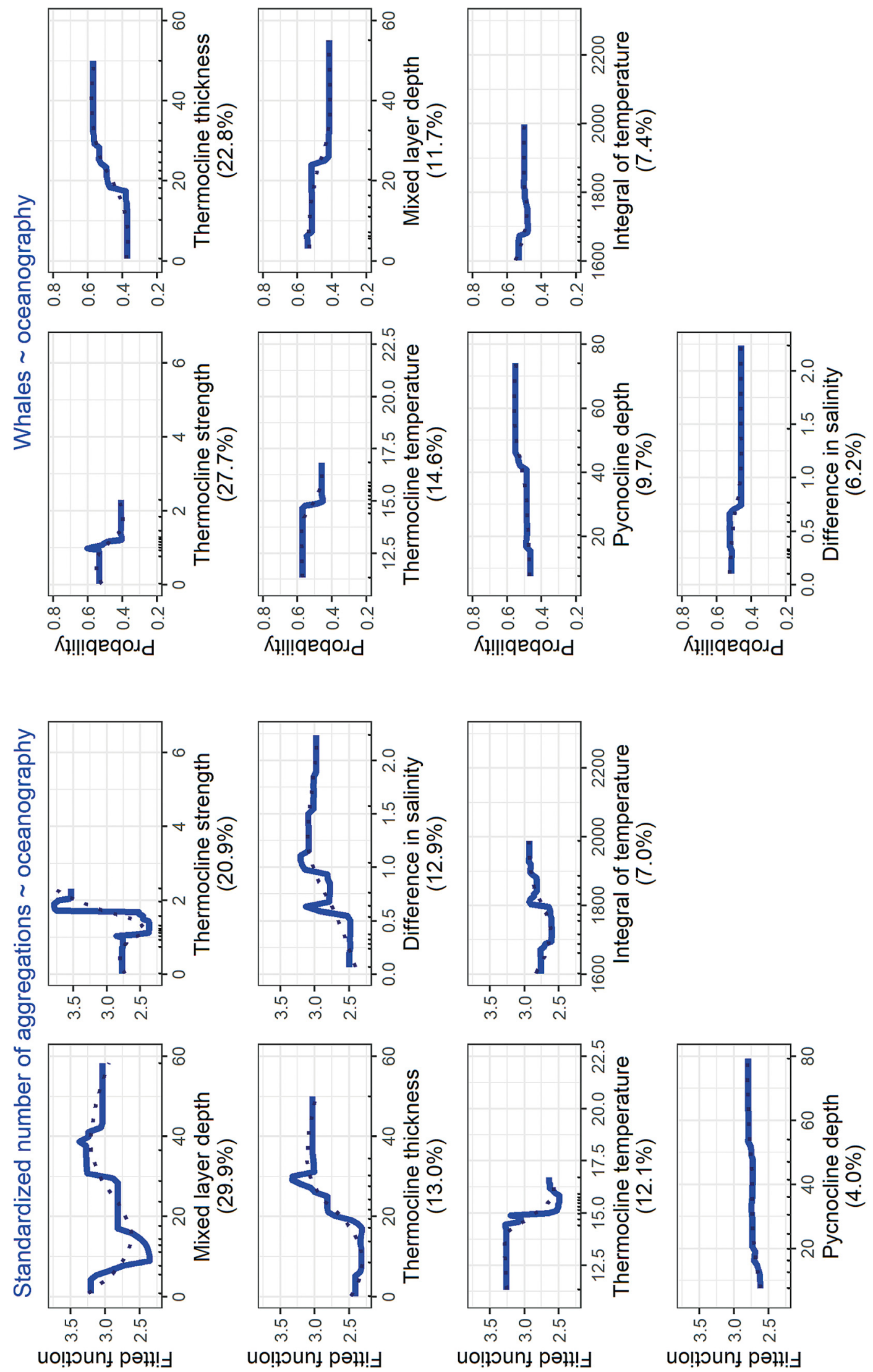

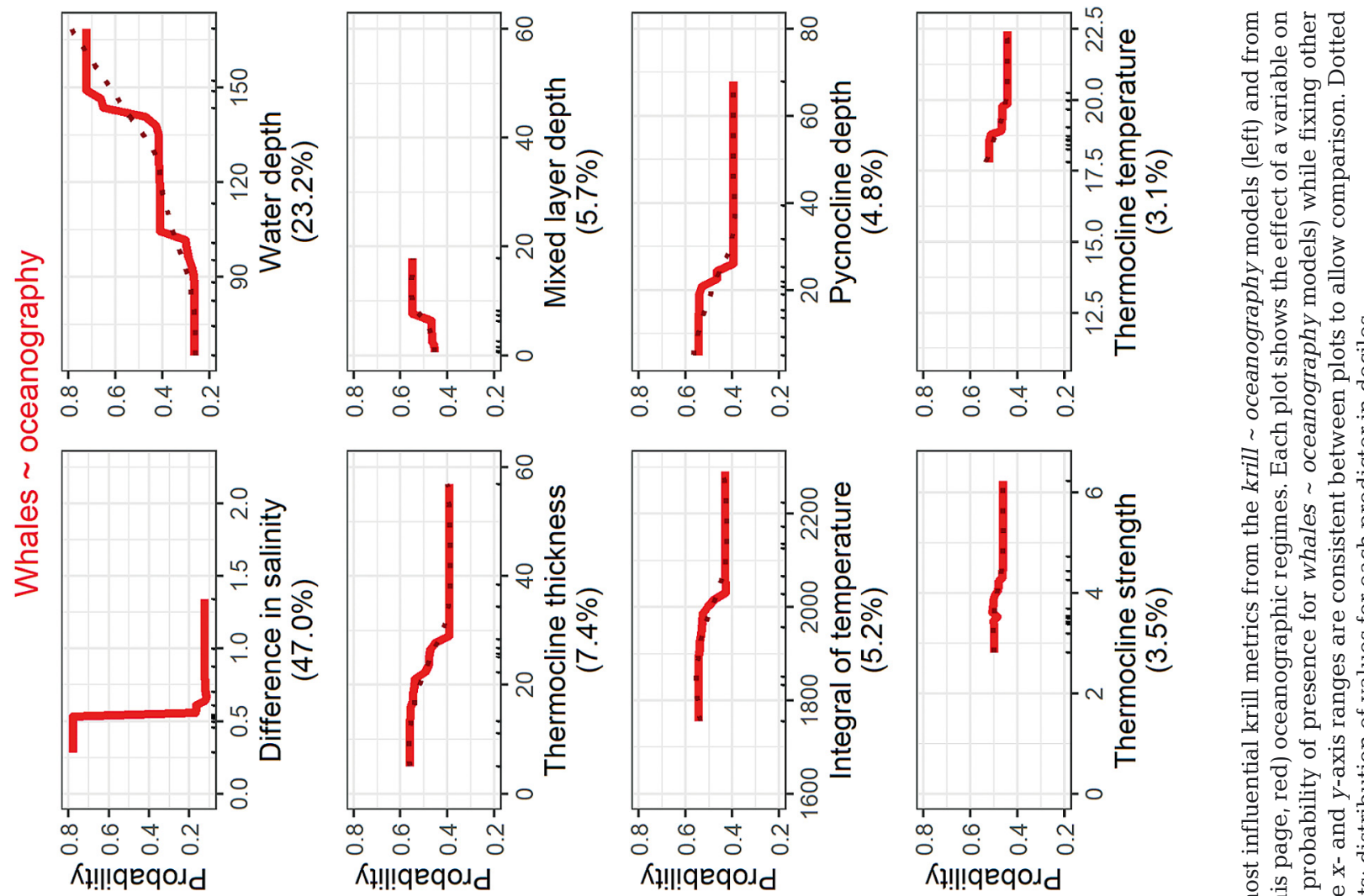

ㄷำ

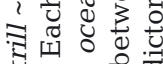

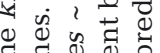

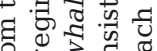

넌 3000

岂.]

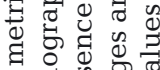

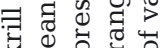

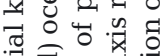

胥

言

药

을 है

e
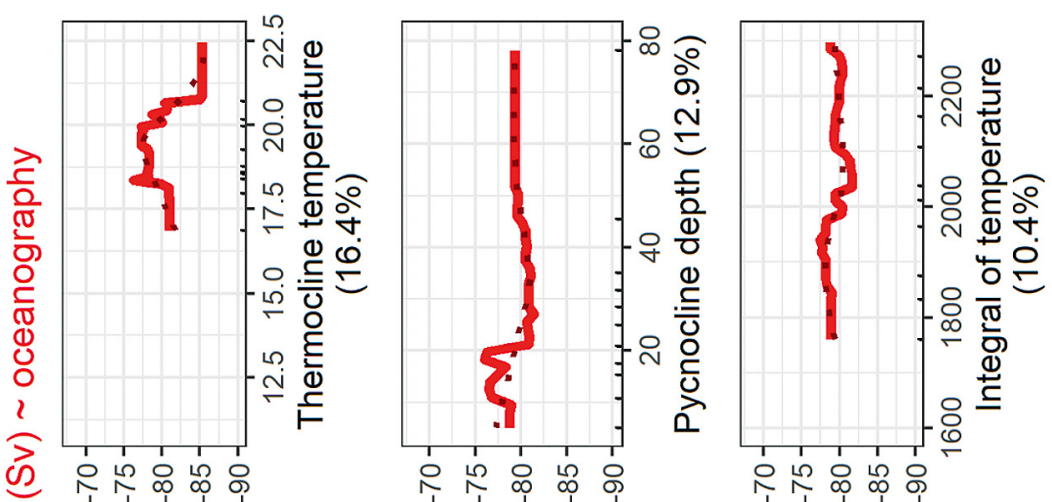

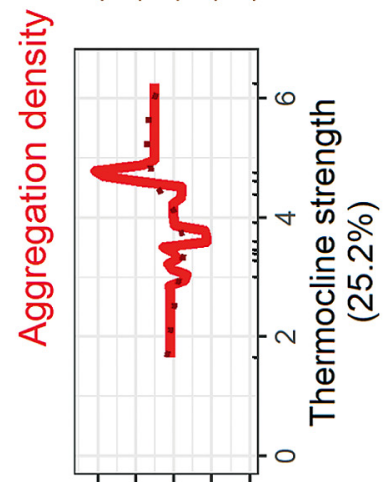

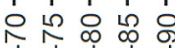

uo!̣ounf pəిt!

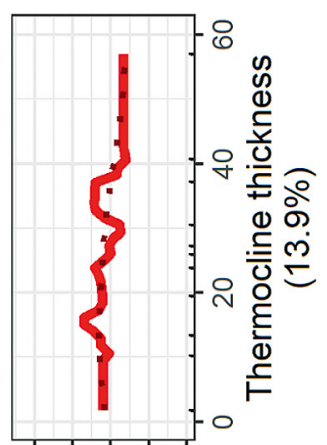

운

uo!ıunf pəH!!

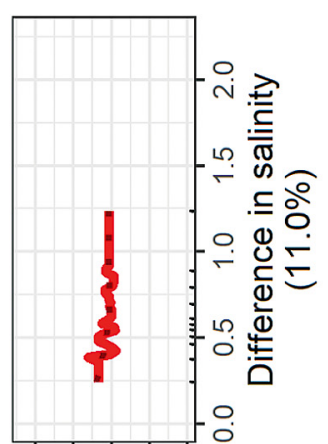

운

uo!̣oun pə॥t!

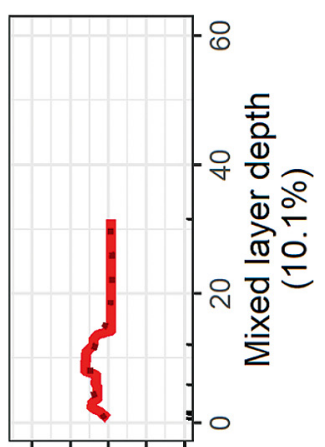

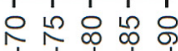

uo!łoun」 pəət!
पै है द्व

थे ठ્ઞ

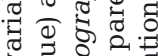

그요졔

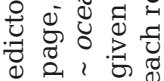

है,

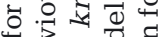

足

है क व

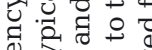

ช

๑ $\Xi$.

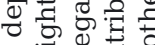

귤 严

늠

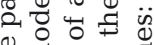

Ð દ્व

द्व द्वे है

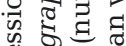

ठ ठ :

ర웡

荧 i

ค สี :

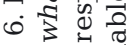

实寻 急 
ferent ranges of the oceanographic metrics measured under the different regimes, particularly the thermocline strength, thickness, and temperature (Figs. $2 \& 6)$.

The predictor variables and response curves of the whales oceanography models differed between regimes (Fig. 6). The typical regime model had a lower CV deviance explained (26.6\%) and AUC score (0.69) than the warm regime model (CV deviance explained $=36.5 \%$ and AUC $=0.87$ ). Although the contribution of the oceanographic predictors was different between regimes, the functional response curves of the whales oceanography models reflected the patterns of the krill oceanography models within each regime. Those oceanographic features driving more krill aggregations (typical model) or higher-density aggregations (warm model) also influenced blue whale presence with similar relationships (Fig. 6). In the typical regime, both krill aggregations and whale presence increased where the thermocline was thicker, where the mixed layer depth was $<10 \mathrm{~m}$ or between 20 and $40 \mathrm{~m}$, and where the pycnocline was deeper, and both decreased with thermocline temperatures $>15^{\circ} \mathrm{C}$. Likewise, in the warm regime, both krill density and blue whale presence increased where difference in salinity was 0.25-0.5 and where the mixed layer depth was 10-20 $\mathrm{m}$, and both decreased with increasing thermocline thickness, warmer thermocline temperature, higher integral of temperature, and deeper pycnocline. The notable exception in both the whales krill and whales oceanography models was that krill and whales had opposite distribution patterns relative to thermocline strength in both regimes; while krill aggregations were more numerous and more dense where the thermocline was stronger, blue whale presence decreased with increasing thermocline strength (Fig. 6).

The inclusion of 2 fluorescence metrics (i.e. integral of fluorescence and surface fluorescence) in the krill oceanography and whales $\sim$ oceanography models in the typical regime only marginally changed the model performance, and decreased the deviance explained slightly in both cases. For number of aggregations, the CV deviance explained was $15.6 \%$ (compared to $16.7 \%$ without fluorescence). For blue whale presence, the CV deviance explained was $23.7 \%$ with fluorescence included among the oceanographic predictor metrics (compared to $26.6 \%$ without). The lack of fluorescence data in 2016 prohibited conducting similar model comparisons with and without fluorescence metrics in the warm regime.

\section{DISCUSSION}

Our models effectively describe the relationships between oceanography, krill, and blue whales and demonstrate the similarities and differences of functional relationships across trophic levels and during variable oceanographic regimes. With climate change, spatial distributions of marine top predators are predicted to shift in response to altered oceanography (Hazen et al. 2013, Schumann et al. 2013, Silber et al. 2017). Understanding the stepwise, functional relationships between environment, prey, and predator provides insight into how predator distribution may change across space and time. This knowledge can be used to inform effective conservation measures and protected area design that reflects the ecology of marine predators rather than only geographic location.

While blue whale distribution has previously been related to in situ physical oceanography and prey (Schoenherr 1991, Croll et al. 1998, 2005, Fiedler et al. 1998, Rennie et al. 2009, Buchan \& Quiñones 2016), this study presents a first quantitative examination of individual functional relationships between physical features of the water column, krill availability, and blue whale distribution. At the foundation of this trophic pathway, the structure of the water column in the STB region differed substantially between the typical oceanographic regimes of 2014 and 2017 relative to the warm regime during 2016 that was characterized by minimal water column mixing. The highly stratified water column in 2016 may also have contributed to the higher performance of the warm regime models, as the system was temperature-dominated and relatively simpler to characterize. Krill aggregations were structured and distributed differently between regimes, with fewer and less dense krill aggregations present inside the STB (north and east of Cape Farewell) during the warm regime. Following these differences in krill availability, blue whale distributions in the STB region were different between regimes, and primarily influenced by number of krill aggregations in typical years but by aggregation density in the warm year. Blue whale preference for different krill metrics between regimes likely reflected a difference in krill availability. In the warm regime, both the standardized number of aggregations and mean aggregation density were lower than in the typical regime. Furthermore, there was more variability in aggregation density than in number of aggregations during the warm regime, causing whales to target areas of relatively high density, 
while the number of aggregations had a negligible impact on their habitat selection (Fig. 7).

The oceanographic features related to more numerous krill aggregations during the typical regime and higher krill density during the warm regime aligned with the features that influenced blue whale presence in each regime respectively. Taken together, these results provide evidence that blue whale distribution is dictated by the availability of their prey, and both prey and predator distribution can be described by similar features of the oceanography. The same oceanographic features that structured the krill influenced the distribution patterns of blue whales in both the warm and typical regimes, even though the ecosystem differed widely between regimes. Therefore, environmental drivers of prey availability can serve as reliable proxies for blue whale distribution, at least at the spatial and temporal scale examined in this study.

The whales $\sim$ krill models produced the highest explanatory power (typical regime CV deviance explained $=31.3 \%$, warm regime CV deviance explained $=60.2 \%$ ), representing the most direct trophic link of all functional relationships modeled in this study. The performance of the whales oceanography models was lower (typical regime CV deviance explained $=26.6 \%$, warm regime CV deviance explained $=36.5 \%$ ). These results contrast the findings of Torres et al. (2008), who determined that environmental features produced far superior predictions of bottlenose dolphin Tursiops truncatus distribution than prey metrics tested through model validations. This discrepancy between studies investigating modeled relationships between predator, prey, and environment may be due to several factors including scale, prey type, and sampling method. Although environmental features are more stable and often easier to sample at relevant scales than prey (due to the patchy and ephemeral nature of the latter) (Torres et al. 2008), the ability to spatially describe a krill prey field using hydroacoustic survey methods may be more effective compared to fish prey sampled using net trawls, as was the case in Torres et al. (2008). Furthermore, our study examines a shorter trophic chain of events between oceanography, krill, and blue whales than the study of Torres et al. (2008), and thus the link between oceanography and whale distribution should be tighter given fewer trophic steps between environment and predator. Although correlative in nature, the findings from our study can be used to infer mechanistic links that drive the distribution of other krill predators such as some baleen whale and seabird species, particularly in upwelling

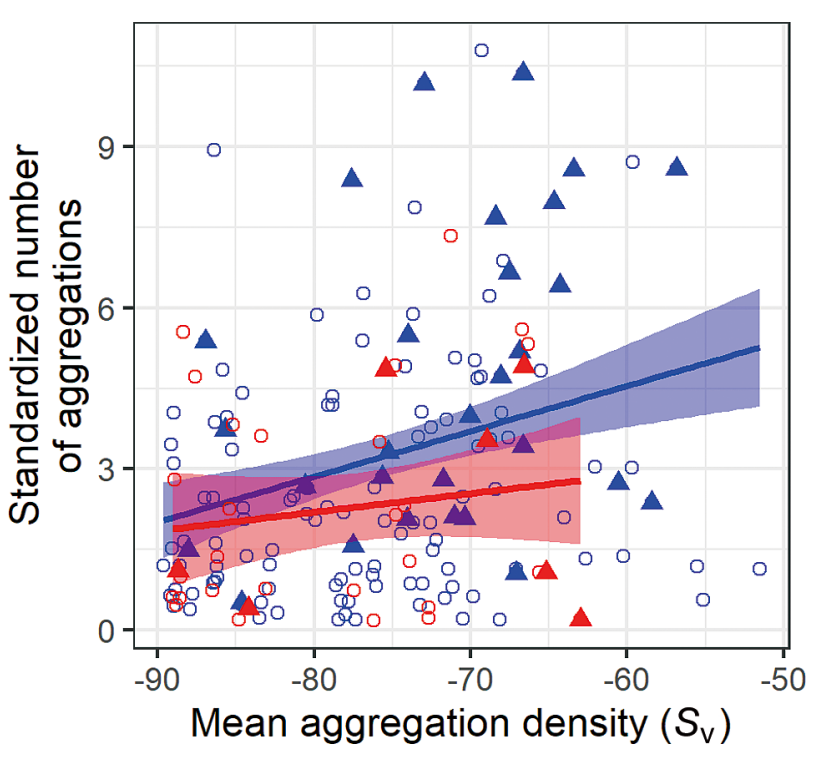

Fig. 7. Relationship between the number of aggregations (standardized by survey effort) and mean aggregation density $\left(S_{\mathrm{v}}\right)$ within each $4 \mathrm{~km}$ grid cell sampled at blue whale presence/background points. Typical regime values are in blue, warm regime values are in red. Triangles represent values at blue whale sighting locations, open circles are values at background point locations

systems. However, caution should be exercised when extrapolating these findings to marine predators that forage on higher trophic level prey such as fish, as there may be more functional links between prey groups not investigated in this study.

A notable difference between the krill oceanography and the whales oceanography models was the different relationships with thermocline strength. While a stronger thermocline was associated with more and denser krill aggregations, whales were preferentially distributed where the thermocline was weaker. Although a stronger thermocline may act as a physical barrier that aggregates krill near or above it (Hampton 1985), blue whales appear to prefer a weaker thermocline. The reason for this discrepancy is unclear. It is also worth noting that thermocline strengths $>2.3$ were only observed in the warm regime. The influence of water depth on blue whale distribution in the warm regime may be an effect of spatial clumping, as the whales were distributed further west in offshore, deeper waters in 2016 (Fig. 1) when there was no prominent plume of cold, upwelled water in the STB. It also must be acknowledged that the spatial distribution of survey effort differed between years, with no effort west of Kahurangi Point in 2014, and less effort west of Kahurangi Point in 2017 than in 2016 (Fig. 1). This discrepancy is an artifact of the sampling design, as search effort was 
directed to locations where blue whales were expected. However, given the oceanographic similarities between 2014 and 2017 and their stark contrast with 2016 despite substantial overlap in spatial coverage between 2016 and 2017, we believe the impact of lower spatial coverage in 2014 on model performance and interpretation is likely minimal.

Despite marked differences in oceanographic conditions between regimes, it was still possible to successfully model trophic links and infer ecological relationships between blue whales, krill, and oceanography. Blue whales altered their ecology in the warm regime, by shifting their spatial distribution further offshore and responding to different aspects of their prey and environment. In addition to the differences in krill availability between regimes (Fig. 7), the warm regime was characterized by much stronger water column stratification (Fig. 2). The offshore areas of the study region are deeper, and with a deeper water column the impact of stratification may not be as great as in the shallower areas north of Farewell Spit (Fig. 1), since the warm surface layer occupies proportionally less of the water column. Hence, blue whales may target the offshore areas in warm regimes because of a lower relative impact of stratification on the deeper water column, as well as greater relative krill abundance (Figs. 4 \& 7). The differences between regimes not only shed light on how blue whale ecology may be influenced by changing ocean conditions, but also highlight the importance of data collection across a range of environmental conditions to accurately capture variability in the system. Had sampling only taken place in typical regime conditions, predicting to a warm regime would necessitate almost complete model extrapolation beyond the range of the calibration data. For example, both the number of krill aggregations and aggregation density decreased with increasing thermocline temperature in both regimes, but what was considered a 'high' thermocline temperature in the typical regime was among the lowest measured values for the warm regime (Figs. 2 \& 6). With variable temperature regimes between years, an overall warming trend in New Zealand's coastal oceans (Sutton \& Bowen 2019), and rising ocean temperatures globally (Field et al. 2014), this study highlights the importance of using relevant calibration data sampled from across a broad range of environmental conditions to allow for inferences that account for changing ocean conditions.

Dynamic management of industrial activity in the STB to protect blue whales could rely on predictive models of blue whale distribution based on remotely sensed data, as satellite imagery is far more accessible than data collected during at-sea survey effort. Spatial predictions using environmental data have demonstrated utility for minimizing overlap between marine megafauna and anthropogenic pressures (Howell et al. 2015, Hazen et al. 2017). In addition to describing the functional relationships between in situ oceanography, krill, and blue whales, this study showed that important oceanographic predictors of krill and blue whale presence, such as thermocline strength, thermocline temperature, and integral of temperature, are highly correlated with sea surface temperature (Pearson's correlation coefficient $=0.96,0.96,0.87$, respectively; Figs. S3 \& S5). Hence, these correlations show promise for future modeling efforts using sea surface temperature data and potentially other oceanographic metrics measured via satellite imagery to infer water column structure, and thereby make informed predictions of blue whale distribution (Becker et al. 2010).

Marine predators integrate multiple trophic levels, and their distribution reflects dynamic ecological processes including physical and biological components of marine ecosystems. As climate regimes change, predators must still locate food to survive, and therefore their spatial distribution is contingent on how their prey are structured and distributed under variable environmental conditions. The increasing frequency of marine heatwaves is emerging as a disruptive pattern linked to global climate change (Oliver et al. 2018, Holbrook et al. 2019), with demonstrated consequences to primary productivity around New Zealand (Chiswell \& Sutton 2020) and changes in zooplankton species composition and abundance in the Tasman Sea (Evans et al. 2020). Marine heatwave conditions have been linked to habitat compression and shifting prey for baleen whale species in upwelling systems (Santora et al. 2020), and more examples will likely emerge as the warming climate and increasing prevalence of marine heatwaves continue to alter species distribution patterns (Becker et al. 2019). This study demonstrates the utility of establishing functional ecological relationships as a foundation for the conservation management of marine predators in changing ocean conditions.

Acknowledgements. Funding for this research was provided by The Aotearoa Foundation, The New Zealand Department of Conservation, The Marine Mammal Institute at Oregon State University, Greenpeace New Zealand, OceanCare, Kiwis Against Seabed Mining, The International Fund for Animal Welfare, The Thorpe Foundation, ARCS Foundation Oregon, and an anonymous donor. The 
project was accomplished through the dedicated work and logistical support of many individuals, including the crew of the RV 'Star Keys' (Western Work Boats, Ltd.) and the RV 'Ikatere' (National Institute of Water and Atmospheric Research, Ltd. [NIWA]), Todd Chandler, Kathy Minta, and Minda Stiles from Oregon State University, Mike Ogle, Callum Lilley, Ian Angus, Laura Boren, Hannah Hendriks, Andrew Lamason, and Dave Lundquist from the New Zealand Department of Conservation, Holger Klinck and Kristin Hodge from Cornell University Bioacoustics Research Program, and Brett Grant and Philip Sutton from NIWA. We also thank David Cade for advice on the hydroacoustic data analysis, and Philip Sutton, Joanne O'Callaghan, Steve Chiswell, Khushboo Jhugroo, and Brett Grant (NIWA) for consultation on the oceanographic data processing and interpretation. Finally, we are grateful to 2 anonymous reviewers for their feedback that improved this manuscript.

\section{LITERATURE CITED}

Abrahms B, Hazen EL, Aikens EO, Savoca MS and others (2019) Memory and resource tracking drive blue whale migrations. Proc Natl Acad Sci USA 116: 5582-5587

* Barbet-Massin M, Jiguet F, Albert CH, Thuiller W (2012) Selecting pseudo-absences for species distribution models: how, where and how many? Methods Ecol Evol 3: 327-338

Barlow J, Gerrodette T, Forcada J (2001) Factors affecting perpendicular sighting distances on shipboard line-transect surveys for cetaceans. J Cetacean Res Manag 3: 201-212

* Barlow DR, Torres LG, Hodge KB, Steel D and others (2018) Documentation of a New Zealand blue whale population based on multiple lines of evidence. Endang Species Res 36:27-40

Becker EA, Forney KA, Ferguson MC, Foley DG, Smith RC, Barlow J, Redfern JV (2010) Comparing California Current cetacean-habitat models developed using in situ and remotely sensed sea surface temperature data. Mar Ecol Prog Ser 413:163-183

Becker EA, Forney KA, Fiedler PC, Barlow J and others (2016) Moving towards dynamic ocean management: How well do modeled ocean products predict species distributions? Remote Sens 8:149

Becker EA, Forney KA, Redfern JV, Barlow J, Jacox MG, Roberts JJ, Palacios DM (2019) Predicting cetacean abundance and distribution in a changing climate. Divers Distrib 25:626-643

* Bernard KS, Steinberg DK (2013) Krill biomass and aggregation structure in relation to tidal cycle in a penguin foraging region off the Western Antarctic Peninsula. ICES J Mar Sci 70:834-849

Bernard KS, Cimino M, Fraser W, Kohut J and others (2017) Factors that affect the nearshore aggregations of Antarctic krill in a biological hotspot. Deep-Sea Res I Oceanogr Res Pap 126:139-147

* Bradford JM, Chapman B (1988) Nyctiphanes australis (Euphausiacea) and an upwelling plume in western cook strait, New Zealand. N Z J Mar Freshw Res 22: 237-247

Bradford-Grieve JM, Murdoch RC, Chapman BE (1993) Composition of macrozooplankton assemblages associ- ated with the formation and decay of pulses within an upwelling plume in greater Cook Strait, New Zealand. N Z J Mar Freshw Res 27:1-22

* Buchan SJ, Quiñones RA (2016) First insights into the oceanographic characteristics of a blue whale feeding ground in northern Patagonia, Chile. Mar Ecol Prog Ser 554:183-199

Buston PM, Elith J (2011) Determinants of reproductive success in dominant pairs of clownfish: a boosted regression tree analysis. J Anim Ecol 80:528-538

Chiswell SM, Sutton PJH (2020) Relationships between long-term ocean warming, marine heat waves and primary production in the New Zealand region. N Z J Mar Freshw Res doi:10.1080/00288330.2020.1713181

Chiswell SM, Zeldis JR, Hadfield MG, Pinkerton $\mathrm{MH}$ (2017) Wind-driven upwelling and surface chlorophyll blooms in Greater Cook Strait. N Z J Mar Freshw Res 51:465-489

* Cotte C, d'Ovidio F, Chaigneau A, Lèvy M, Taupier-Letage I, Mate B, Guinet C (2011) Scale-dependent interactions of Mediterranean whales with marine dynamics. Limnol Oceanogr 56:219-232

* Croll DA, Tershy BR, Hewitt RP, Demer DA and others (1998) An integrated approach to the foraging ecology of marine birds and mammals. Deep-Sea Res II Top Stud Occeanogr 45:1353-1371

Croll DA, Marinovic B, Benson S, Chavez FP, Black N, Ternullo R, Tershy BR (2005) From wind to whales: trophic links in a coastal upwelling system. Mar Ecol Prog Ser 289:117-130

* Derville S, Constantine R, Baker CS, Oremus M, Torres LG (2016) Environmental correlates of nearshore habitat distribution by the Critically Endangered Māui dolphin. Mar Ecol Prog Ser 551:261-275

* Derville S, Torres LG, Iovan C, Garrigue C (2018) Finding the right fit: comparative cetacean distribution models using multiple data sources and statistical approaches. Divers Distrib 24:1657-1673

Elith J, Leathwick JR (2009) Species distribution models: ecological explanation and prediction across space and time. Annu Rev Ecol Evol Syst 40:677-697

Elith J, Leathwick JR, Hastie T (2008) A working guide to boosted regression trees. J Anim Ecol 77:802-813

Escobar-Flores P, O'Driscoll RL, Montgomery JC (2013) Acoustic characterization of pelagic fish distribution across the South Pacific Ocean. Mar Ecol Prog Ser 490: 169-183

Evans R, Lea MA, Hindell MA, Swadling KM (2020) Significant shifts in coastal zooplankton populations through the 2015/16 Tasman Sea marine heatwave. Estuar Coast Shelf Sci 235:106538

Fiedler PC (2010) Comparison of objective descriptions of the thermocline. Limnol Oceanogr Methods 8: 313-335

*Fiedler PC, Reilly SB, Hewitt RP, Demer D and others (1998) Blue whale habitat and prey in the California Channel Islands. Deep-Sea Res II Top Stud Oceanogr 45: 1781-1801

Fiedler PC, Mendelssohn R, Palacios DM, Bograd SJ (2013) Pycnocline variations in the Eastern Tropical and North Pacific, 1958-2008. J Clim 26:583-599

Field CB, Barros VR, Dokken DJ, Mach KJ and others (2014) Climate change 2014: impacts, adaptation and vulnerability. A. Global and sectoral aspects. Working Group II contribution to the Fifth Assessment Report of the In- 
tergovernmental Panel on Climate Change. Cambridge University Press, Cambridge

Friedman JH, Meulman JJ (2003) Multiple additive regression trees with application in epidemiology. Stat Med 22: 1365-1381

Gill P (2002) A blue whale (Balaenoptera musculus) feeding ground in a southern Australian coastal upwelling zone. J Cetacean Res Manag 4:179-184

* Greenwell B (2017) pdp: an R package for constructing partial dependence plots. R J 9:421-436

Greenwell B, Boehmke B, Cunningham J, Developers G (2019) Gbm: generalized boosted regression models. R package version 2.1.5. https://cran.r-project.org/web/ packages/gbm/index.html

Hampton I (1985) Abundance, distribution and behaviour of Euphausia superba in the Southern Ocean between 15 and $30^{\circ}$ E during FIBEX. In: Siegfried WR, Condy PR, Laws RM (eds) Antarctic nutrient cycles and food webs. Springer, Berlin, p 294-303

Hazen EL, Jorgensen S, Rykaczewski RR, Bograd SJ and others (2013) Predicted habitat shifts of Pacific top predators in a changing climate. Nat Clim Chang 3: 234-238

*Hazen EL, Friedlaender AS, Goldbogen JA (2015) Blue whales (Balaenoptera musculus) optimize foraging efficiency by balancing oxygen use and energy gain as a function of prey density. Sci Adv 1:e1500469

*Hazen EL, Palacios DM, Forney KA, Howell EA and others (2017) WhaleWatch: a dynamic management tool for predicting blue whale density in the California Current. J Appl Ecol 54:1415-1428

*Hijmans RJ, Phillips S, Leathwick JR, Elith J (2017) Dismo: species distribution modeling. $\mathrm{R}$ package version 1.1-4. https://rdrr.io/cran/dismo/

*Hoegh-Guldberg O, Bruno JF (2010) The impact of climate change on the world's marine ecosystems. Science 328: 1523-1528

Holbrook NJ, Scannell HA, Sen Gupta A, Benthuysen JA and others (2019) A global assessment of marine heatwaves and their drivers. Nat Commun 10:2624

Howell EA, Hoover A, Benson SR, Bailey H, Polovina JJ, Seminoff JA, Dutton PH (2015) Enhancing the TurtleWatch product for leatherback sea turtles, a dynamic habitat model for ecosystem-based management. Fish Oceanogr 24:57-68

Hyrenbach KD, Forney KA, Dayton PK (2000) Marine protected areas and ocean basin management. Aquat Conserv 10:437-458

Kinsman B (1969) Historical notes on the original Beaufort scale. Mar Obs 39:116-124

* Lawson GL, Wiebe PH, Stanton TK, Ashjian CJ (2008) Euphausiid distribution along the Western Antarctic Peninsula. A. Development of robust multi-frequency acoustic techniques to identify euphausiid aggregations and quantify euphausiid size, abundance, and biomass. Deep-Sea Res II Top Stud Oceanogr 55: $412-431$

Maxwell SM, Ban NC, Morgan LE (2014) Pragmatic approaches for effective management of pelagic marine protected areas. Endang Species Res 26:59-74

Nickels CF, Sala LM, Ohman MD (2018) The morphology of euphausiid mandibles used to assess selective predation by blue whales in the southern sector of the California Current System. J Crustac Biol 38:563-573

Nicol S, Pauly T, Bindoff NL, Wright S and others (2000)
Ocean circulation off east Antarctica affects ecosystem structure and sea-ice extent. Nature 406:504-507

Oliver ECJ, Benthuysen JA, Bindoff NL, Hobday AJ, Holbrook NJ, Mundy CN, Perkins-Kirkpatrick SE (2017) The unprecedented 2015/16 Tasman Sea marine heatwave. Nat Commun 8:16101

* Oliver ECJ, Donat MG, Burrows MT, Moore PJ and others (2018) Longer and more frequent marine heatwaves over the past century. Nat Commun 9:1324

*Palacios DM, Baumgartner MF, Laidre KL, Gregr EJ (2013) Beyond correlation: integrating environmentally and behaviourally mediated processes in models of marine mammal distributions. Endang Species Res 22: 191-203

*Palacios DM, Bailey H, Becker EA, Bograd SJ and others (2019) Ecological correlates of blue whale movement behavior and its predictability in the California Current Ecosystem during the summer-fall feeding season. Mov Ecol 7:26

* Paradis E, Schliep K (2019) ape 5.0: an environment for modern phylogenetics and evolutionary analyses in R. Bioinformatics 35:526-528

* Pirotta E, Mangel M, Costa DP, Mate B and others (2018) A dynamic state model of migratory behavior and physiology to assess the consequences of environmental variation and anthropogenic disturbance on marine vertebrates. Am Nat 191:E40-E56

Poloczanska ES, Brown CJ, Sydeman WJ, Kiessling W and others (2013) Global imprint of climate change on marine life. Nat Clim Change 3:919-925

R Core Team (2019) R version 3.6.1: a language and environment for statistical computing. R Foundation for Statistical Computing, Vienna

* Redfern JV, Ferguson MC, Becker EA, Hyrenbach KD and others (2006) Techniques for cetacean-habitat modeling. Mar Ecol Prog Ser 310:271-295

Rennie S, Hanson CE, McCauley RD, Pattiaratchi C and others (2009) Physical properties and processes in the Perth Canyon, Western Australia: links to water column production and seasonal pygmy blue whale abundance. J Mar Syst 77:21-44

* Santora JA, Mantua NJ, Schroeder ID, Field JC and others (2020) Habitat compression and ecosystem shifts as potential links between marine heatwave and record whale entanglements. Nat Commun 11:536

* Schoenherr JR (1991) Blue whales feeding on high concentrations of euphausiids around Monterey submarine canyon. Can J Zool 69:583-594

Schumann N, Gales NJ, Harcourt RG, Arnould JPY (2013) Impacts of climate change on Australian marine mammals. Aust J Zool 61:146-159

Shirtcliffe TGL, Moore MI, Cole AG, Viner AB, Baldwin R, Chapman B (1990) Dynamics of the Cape Farewell upwelling plume, New Zealand. N Z J Mar Freshw Res 24:555-568

* Silber GK, Lettrich MD, Thomas PO, Baker JD and others (2017) Projecting marine mammal distribution in a changing climate. Front Mar Sci 4:413

Stevens CL, O'Callaghan JM, Chiswell SM, Hadfield MG (2019) Physical oceanography of New Zealand/Aotearoa shelf seas - a review. N Z J Mar Freshw Res, doi:10.1080/ 00288330.2019 .1588746

* Sutton PJH, Bowen M (2019) Ocean temperature change around New Zealand over the last 36 years. N Z J Mar Freshw Res 53:305-326 
Swets JA (1988) Measuring the accuracy of diagnostic systems. Science 240:1285-1293

Sydeman WJ, Poloczanska E, Reed TE, Thompson SA (2015) Climate change and marine vertebrates. Science 350: 772-777

Torres LG (2013) Evidence for an unrecognised blue whale foraging ground in New Zealand. N Z J Mar Freshw Res 47:235-248

Torres LG, Read AJ, Halpin P (2008) Fine-scale habitat modeling of a top marine predator: Do prey data improve

Editorial responsibility: Peter Corkeron,

Woods Hole, Massachusetts, USA predictive capacity? Ecol Appl 18:1702-1717

Torres LG, Smith TD, Sutton P, Macdiarmid A, Bannister J, Miyashita T (2013) From exploitation to conservation: Habitat models using whaling data predict distribution patterns and threat exposure of an endangered whale. Divers Distrib 19:1138-1152

* Torres LG, Barlow DR, Chandler TE, Burnett JD (2020) Insight into the kinematics of blue whale surface foraging through drone observations and prey data. PeerJ 8:e8906

Submitted: January 9, 2020; Accepted: April 20, 2020

Proofs received from author(s): May 15, 2020 